\title{
MAINTENANCE GROUPING OPTIMIZATION FOR OFFSHORE WIND TURBINE CONSIDERING OPPORTUNITIES BASED ON ROLLING HORIZON APPROACH
}

\author{
Yang Lua ${ }^{1}$ \\ Liping Suna ${ }^{1}$ \\ Jichuan Kanga ${ }^{1}$ \\ Xinyue Zhang ${ }^{2}$ \\ ${ }^{1}$ College of Shipbuilding Engineering, Harbin Engineering University, Harbin, China \\ ${ }^{2}$ Heilongjiang Water Transport Planning and Design Institute, Harbin, China
}

\begin{abstract}
In future, offshore wind turbines may be consider a crucial part in the supply of energy. Maintenance processes are directed to attain a safe and reliable operation of offshore machines and wind turbines. In this paper, an opportunistic maintenance strategy for offshore wind turbine is proposed, considering imperfect maintenance and the preventive maintenance durations. Reliability Centric Maintenance serves as a proactive tactic to operations and maintenance by inhibiting the possible reasons of poor performance and controlling failures. Other components can implement the opportunistic preventive maintenances if one component has reached its reliability threshold. According to the rolling horizon approach, it is of great importance to update the maintenance planning for the sake of the short-term information. By figuring out the best combination, the maintenance schedule in the mission time has been finally determined. Failure information are obtained from previous studies to accomplish the calculations. The outcomes indicate that the maintenance cost has been dramatically reduced through the application of opportunistic maintenance.
\end{abstract}

Keywords: offshore wind turbine; opportunistic maintenance; rolling horizon; imperfect maintenance; preventive maintenance durations

\section{INTRODUCTION}

Offshore wind farms provide substantial energy production compared to onshore farms regarding wind quality and deployment area availability. In a scenario, where half of Europe's electricity demand by 2050 will be fulfilled through the wind energy, the majority of this power shall be produced offshore, highlights the absence of land availability for development [8].

Cost is the major limitation of the development of offshore wind turbines (OWTs) [30]. The installation and maintenance of a wind turbine at sea needs high infrastructure and better resources, which in turn makes them difficult to install and operate offshore. The difficulties in accessing and maintaining offshore wind turbines (OWTs) lead to increased operation and maintenance costs, this is because of the fact that only specific transportation resources can be used to supply maintenance sites for OWTs, and subsequently, increased cost of energy [24].
Moreover, the extreme marine operating conditions such as salt-fog, humidity, sea ice and typhoon will result in a higher failure rate in comparisons with onshore ones. In turn, this will lead to more maintenance cost $[25,31]$. According to Snyder and Kaiser [26], the maintenance and operation of an offshore wind farm contribute to a very high cost. Optimizing schedule maintenance can be one of the cost-effective way. In this research, a maintenance cost model corresponding with opportunistic maintenance (OM) strategy, is promoted and the procedure of the costs minimization is adopted.

Previous studies are conducted to optimize the maintenance cost of onshore wind turbines (WTs). A host of fundamentals, technologies and economics of WTs was provided by Hau [12]. Bertling and Besnard [2] promoted a model which is used to optimize the condition-oriented maintenance of the WT components, for which the degradation will be classified into different categories based on the damage level. Carlos et al. [3] optimized the onshore wind farms maintenance based on stochastic model. Ding and Tian $[6,7]$ promoted an approach 
to make comparisons among three optimization models. According to them, preventive maintenance (PM) has three models, including an imperfect model, a perfect model and a two-level model. In both studies, OM following imperfect two-level action was found to be optimum for WT. Asgarpoor and Kahrobaee [15] investigated how a hybrid analyticalsimulation method is going to work for the optimization of the maintenance of the deteriorating equipment via the case study concerning WTs. Laggoune et al. [18] had a consideration of the opportunistic components replacement via the components grouping. It is conducted in such a way that replacement times of every component in this group actually are an integer multiple of the least replacement time. Under such case, it is not optimal to have such wide component replacement, though the system wide optimization is indeed possible.

OWT's maintenance grouping optimization has been recently attached with great attention. Laura and Vincente [19] analyzed the lifecycle cost for offshore wind farms. Bertling and Nilsson [22] illustrated the effect of condition monitoring as two cases' maintenance strategies, including a wind farm offshore and a single turbine onshore. With reference to their study, the cost of the strategy and also the maintenance management of the offshore power systems are benefited from the condition monitoring process. These costs will be covered by $0.43 \%$ increase of the availability of turbines used for power generation. Karyotakis and Bucknall [17] planned intervention as a maintenance and repair strategy for OWTs. Sorensen [27] proposed a framework for risk-based planning of operation and maintenance for OWTs. Arshad and O'Kelly [1] proposed different ideas with respect to maintenance operation and costs by reviewing different OWT structures. Carroll [4] provided failure rate, repair time and unscheduled O\&M cost analysis of OWTs. Two different maintenance strategies, namely conditionbased and corrective maintenance was compared by Nielsen and Sorensen [21] for a generic OWT with single component. Besnard et al. [2] proposed a model for OWT maintenance support organization, considering modes of transportation for maintenance, location of maintenance team, service hours, and number of teams as decision variables. Hameed and Vatn [10] analyzed the role of grouping in the development of an overall maintenance optimization framework for OWTs.

OWTs' maintenance activities sometimes are conducted in harsh operating conditions. Generally speaking, the PM activity is not that perfect. For example, it fails to restores the system and change it back to the as-good-as-new status $[6,7]$. In this research, imperfect PM is taken into the consideration. The age reduction factor is also taken into consideration to model the imperfect PM. The downtime caused by wind farms' insufficient accessibility will also be taken into consideration in this study. The rolling horizon method promoted by Wildeman et al [32] is adopted, which can help to update the maintenance plan easily according to the short-term information. The optimal PM activities are decided via the maximization of the OWT system's OM short-term cost savings.

In this research, the OM model is promoted so that the OWT system's maintenance cost can be optimized according to the rolling horizon approach. Section 2 presents the system description and assumptions. Section 3 presents the analysis of the development of the rolling horizon approach in a condition with many maintenance constraints. Two optimization conditions (imperfect maintenance and perfect maintenance) are illustrated in this section. OWT's statistical data are presented in Section 4 to achieve the goal of grouping maintenance optimization. The calculated results are also discussed. Conclusions are addressed in the last section.

\section{SYSTEM DESCRIPTION AND ASSUMPTIONS}

\section{SYSTEM DESCRIPTIONROTON}

A OWT system consists of various components, which are either independent or auxiliary to each other to guarantee the performance of the entire system. OWTs include critical mechanical components such as rotors, gearbox, generators and pitch mechanisms, they cost more than $30 \%$ of total capital expenditure for offshore wind project [14]. Fig. 1 shows the composition of OWT system.

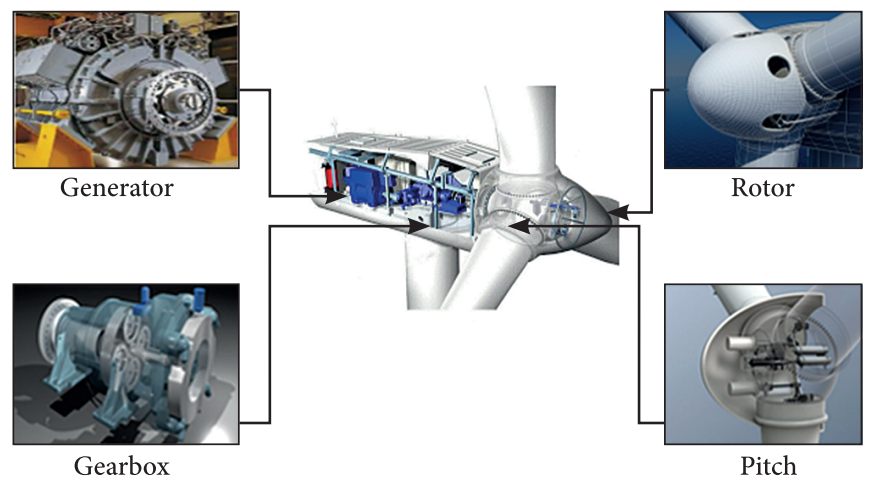

Fig. 1. The critical components of OWT system

\section{ROTOR}

Rotor, the core component of OWTs system is divided into three parts in literature: rotor blades, rotor hub and rotor bearings. The rotor blades are the components of the wind turbine with the highest percentage in term of downtimes. The leaves are primarily associated with physical failures, like low strength and low energy fibrous materials, cracks, corrosion and delamination, that appear in the principal and irregular edges of the blades [16]. The effective lifetime of an offshore wind turbine blade is shorter than onshore. The former has the drawback of rotor-blades experiencing higher mechanical stress and environmental damages in marine locations [24]. The rotor hub is usually made from cast iron [29], consisting of electrical and mechanical equipment inside for regulating the blades. The hub bolsters dense loads accounting to clearance relaxing of the imbalance, blade root, surface unevenness and cracks [11]. The bearing has a very high synthetic mechanical property to sustain the load/torque during the start and shutdown of the OWTs. Bearings held between hub and blades can be damaged due to 
wears, prompting the distortion of external facade, overheating and spalling the parts of the bearings [20].

\section{GEARBOX}

Gearbox is required to tie the rotational speed to the desired speed of the electric generator. The gearbox failure is one of the most typical failures [13]. Many studies in literature explain the standard gearbox failures, as they cause significant downtimes in the OWTs system [28]. Gearbox damage is mainly caused by the shock load caused by the unstable wind speed and the salty air which contribute to erosion. In addition, a long time is required to fix the gearbox in case of a shutdown, due to its size and high installation position.

\section{GENERATOR}

The generator is connected to the electrical system and supplies the transformed energy to the electrical system. The generator failure is generally attributable to high temperature, abnormal speed, stator insulation damage, inter turn short circuit, bearing damage, collector ring fault etc. [33].

\section{PITCH}

The pitch is the major contributor of overall OWT failures through collected records [23]. It is precisely interconnected to the blades of the rotor. Its primary objective is to adjust the output power at high functioning wind speeds. Pitch regulation changes the control of the framework to estimate blade position, gauge power output and inculcate fluctuations of the pitch by varying the rotor geometry. Pitch regulation enables to start the wind-powered turbine swiftly as wind increases [5]. The turbulence of wind causes pitch system faults.

\section{ASSUMPTIONS}

Because of the complexity of wind turbine components and actual maintenance actions, it is necessary to simplify the system. The proposed maintenance strategy is based on the assumptions below:

(1) The wind turbine system is reduced to four main components (rotor, gearbox, generator and pitch). All the components are independent and follow a Weibull distribution with a scale parameter $\alpha$ and a shape parameter $\beta$, then:

$$
\lambda_{i}(t)=\frac{\beta_{i}}{\alpha_{i}} \times\left(\frac{t}{\alpha_{i}}\right)^{\beta_{i}-1}
$$

(2) Whenever the component fails, a corrective maintenance is performed. Corrective maintenance can only recover the component's function and it cannot change the component's failure rate.

(3) Whenever the component reaches its reliability threshold, a PM action will be implemented. This assumption assures that the proposed imperfect PM model is reliability-centered, which implies that the failure risk in each PM cycle is equal. After the
PM action, the component begins a new degradation process because of the imperfect PM effect.

(4) As all the components actually are in series, it is reliable to assume that all the components in this system will have the same downtime cost named $C_{d}$ in the PM activities. That implies $C_{d 1}=\ldots=C_{d n}=C_{d}$. We also assume that the duration of PM for every component is equal to $\tau_{i}$ which means $\tau_{i 1}=\ldots=\tau_{i n}=\tau_{i}$.

\section{EXTENSION OF ROLLING HORIZON APPROACH}

This section presents a dynamic maintenance grouping approach used for the OWT maintenance optimization. The proposed approach is modified according to the rolling horizon approach and has been classified into 5 phases:

\section{PHASE 1: INDIVIDUAL OPTIMIZATION}

Just like what is described in Section 1, the function of the failure rate before and after the maintenance has been listed as follows:

The PM of every component is equal periodic for the perfect maintenance. The PM activity changes the system back to the as-good-as-new status $\left(a_{1}=0\right)$. The function of the failure rate before and after the maintenance is:

$$
\lambda_{i, j+1}(t)=\lambda_{i, j}(t)
$$

Where $\lambda_{i, j}(t)$ is the failure rate function of component i prior to the $j$-th PM.

The PM of every component actually is unequal periodic for the imperfect maintenance. The PM activity is adopted for the imperfect maintenance actions' modeling which cannot change the system back to the initial status $\left(0<\alpha_{i}<1\right)$. The connection between the functions of the failure rate before and after the $\mathrm{j}$-th PM is defined as follows

$$
\lambda_{i, j+1}(t)=\lambda_{i, j}\left(t+a_{i} \times \Delta t_{i, j}\right)
$$

Where $\Delta t_{i, j}$ is the PM interval of component $\mathrm{i}$ prior to the j-th PM.

According to the assumptions, PM activity is performed for component $i$ if it reaches the threshold $R_{i}$. In such an instance, a reliability equation can be constructed as

$\exp \left[-\int_{0}^{\Delta t_{1, j}} \lambda_{1, j}(t) d t\right]=\exp \left[-\int_{0}^{\Delta t_{2, j}} \lambda_{2, j}(t) d t\right]=\ldots=\exp \left[-\int_{0}^{\Delta t_{i, j}} \lambda_{i, j}(t) d t\right]=R_{i}$

Eq. (4) can be rewritten as

$$
\int_{0}^{\Delta t_{1, j}} \lambda_{1, j}(t) d t=\int_{0}^{\Delta t_{2, j}} \lambda_{2, j}(t) d t=\ldots \int_{0}^{\Delta t_{i, j}} \lambda_{i, j}(t) d t=-\ln R_{i}
$$

Where $\int_{0}^{\Delta t_{i, j}} \lambda_{i, j}(t) d t$ represents the cumulative failure risk of component $i$ in maintenance cycle $j$, implying that the number of corrective repair for component $i$ in each maintenance cycle is equal to $-\ln R_{i}$. 
$T$ represents the mission time, for the perfect maintenance, the expected maintenance cost per unit time for component i can be calculated as follows:

$$
E C_{i}=\left[C_{0}+C_{m(i)}\left(-\ln R_{i}\right)+C_{p(i)}+C_{d(i)} \tau_{i, j}\right] /\left(\Delta t_{i, j}+\tau_{i, j}\right)
$$

Where $\tau_{i, j}$ is the duration of PM, $C_{m(i)}$ is the corrective maintenance cost which includes the repair cost and the downtime cost during the maintenance. $C_{p(i)}$ and $C_{d(i)}$ represent once preventive maintenance cost for component $i$ and downtime cost per unit time for a PM action, respectively.

For the imperfect maintenance, assuming the number of PM actions for component $i$ during the mission time is $N_{i}$, the average maintenance cost for component i can be evaluated as

$$
E \bar{C}_{i}=\left\{N_{i}\left[C_{0}+C_{m(i)}\left(-\ln R_{i}\right)+C_{p(i)}^{\prime}+C_{d(i)} \tau_{i, j}\right]\right\} / \sum_{j=1}^{N_{i}}\left(\Delta t_{i, j}+\tau_{i, j}\right)
$$

Where $C_{p(i)}^{\prime}$ is preventive maintenance cost of component $i$, its value is related to $\alpha_{i}$ and $C_{p(i)}$, which can be expressed as $C_{p(i)}^{\prime}=\left(1-a_{i}\right)^{2} \times C_{p(i)}$

Eq. (7) satisfies $\sum_{j=1}^{N_{i}-1}\left(\Delta t_{i, j}+\tau_{i, j}\right)<T<\sum_{j=1}^{N_{i}}\left(\Delta t_{i, j}+\tau_{i, j}\right)$.

$\Delta t_{i, j}$ represents the individual optimal PM interval length, which can be calculated from Eq. (5), and it is a function of $R_{i}$. The optimal PM reliability threshold $R_{i}$ for component i can be decided through the minimization of the $C E_{i}$. The obtaining of reliability threshold $R_{i}$ is the basis of the following opportunistic PM model.

\section{PHASE 2: TENTATIVE PLANNING}

This phase targets on building up all tentative maintenance dates, assuming that the maintenance activities are conducted separately in the interval time of PM. Based on the nominal preventive maintenance frequencies, the first tentative maintenance execution time of component $i(i=1, \ldots, n)$ denoted $t_{i, 1}$ can be calculated by

$$
t_{i, 1}=t_{\text {begin }}+\Delta t_{i, 1} \quad \text { if } \quad j=1
$$

Where $t_{\text {begin }}$ is the current date, without loss of generality we can set $t_{\text {begin }}=0$. Based on the individual optimal PM interval length $\Delta t_{i, j}$ of phase 1 , let $t_{i, j}$ denote the $j$-th PM time of component $i$ since $t_{\text {begin }}$ in the scheduling horizon, the tentative execution time of $t_{i, j}$ is determined as follow:

$$
t_{i, j}=t_{i, j-1}+\Delta t_{i, j-1}+\tau_{i, j-1} \quad \text { if } \quad j>1
$$

After this phase, all PM activities' tentative execution times in the scheduling horizon have been defined.

\section{PHASE 3: ECONOMIC PROFIT FORMULATION}

This phase is mainly about creating economic profits when the PM activities are carried out simultaneously. The PM activities grows for other components if one of the components (suppose component $k$ ) hits its reliability threshold in the $n$-component series system. It suggests that the component $i(i \neq k)$ has the opportunity to remain together with component $k$ or with any other component when component $k$ during the $\tau_{k, j}$ time for the $j$-th preventive maintenance. The corresponding economic profit of such a group can be classified into four phases listed as follows if the components $i$ and $k$ have been simultaneously maintained:

$$
C_{S(i, k, j)}=C_{0}+C_{D(i, k, j)}+C_{M(i, k, j)}-C_{P(i, k, j)}
$$

Where $C_{D(i, k, j)}$ is the downtime cost saving when components $i$ and $k$ are simultaneously maintained for the $j$-th maintenance, which can be shown as

$$
C_{D(i, k, j)}=C_{d(i)} \times \tau_{k}
$$

$C_{M(i, k, j)}$ is the maintenance cost saving because of the maintenance of component $\mathrm{i}$ in advance which leads to reduction of the unexpected failure. Then $C_{M(i, k, j)}$ can be expressed as

$$
C_{M(i, k, j)}=\left[\left(-\ln R_{i}\right)-\left(-\ln R_{i, k}\right)\right] C_{m(i)}
$$

Where $R_{i, k}$ is the reliability of component $i$ when component $i$ is simultaneously maintained with component $k$. Furthermore, all of the scheduled PM times will change due to the advancement of the PM action. Suppose $\Delta t_{i, j}$ is the original PM schedule and $\Delta t_{i, j}^{\prime}$ is the new PM schedule, the cumulative time shift from the old one to the new one should be

$$
\delta t_{i, k}=\sum_{j=1}^{M}\left(\Delta t_{i, j}-\Delta t_{i, j}^{\prime}\right) \quad M=\min \left\{N_{i}, N_{i}^{\prime}\right\}
$$

Where $N_{i}$ is the time of original PM schedule, is $N^{\prime}{ }_{i}$ the time of new PM schedule. $\Delta t_{i, j}$ satisfies

$$
\int_{0}^{\Delta t_{i, 1}} \lambda_{i, 1}(t) d t=\int_{0}^{\Delta t_{i, 2}} \lambda_{i, 2}(t) d t=\ldots=\int_{0}^{\Delta t_{i, j}} \lambda_{i, j}(t) d t=-\ln R_{i}
$$

and $\Delta t_{i, j}^{\prime}$ satisfies

$$
\begin{aligned}
& \int_{0}^{\Delta t_{i, 1}^{\prime}} \lambda_{i, 1}(t) d t=-\ln R_{i, k} \\
& \int_{0}^{\Delta t_{i, 2}^{\prime}} \lambda_{i, 2}^{\prime}(t) d t=\int_{0}^{\Delta t_{i, 3}^{\prime}} \lambda_{i, 3}^{\prime}(t) d t=\ldots=\int_{0}^{\Delta t_{i, j}^{\prime}} \lambda_{i, j}^{\prime}(t) d t=-\ln R_{i}
\end{aligned}
$$

The original failure rate function $\lambda_{i, j}(t)$ and the new failure rate function $\lambda_{i, j}^{\prime}(t)$ can be deduced from Eq. (3). Therefore the penalty cost for component $i$ to advance the PM action is 


$$
C_{P(i, k, j)}=E \bar{C}_{i} \times \delta t_{i, k}=E \bar{C}_{i} \times \sum_{j=1}^{M}\left(\Delta t_{i, j}-\Delta t_{i, j}^{\prime}\right)
$$

From Eq. (12) to (16), the OM cost saving can be obtained when components $i$ and $k$ are simultaneously maintained for the $j$-th maintenance. If $C_{s(i, k, j)}<0$ the grouping implies a negative economic dependence. Consequently, the group components should not be simultaneously maintained. If $C_{s(i, k, j)}>0$ the grouping leads to a positive economic dependence and we can consider the components $i$ and $k$ simultaneously maintained.

In the next phase, a combination of OM activities for each component is chosen, and the best one based on the opportunistic cost $C_{s(i, k, j)}$ is selected.

\section{PHASE 4: COMBINING MAINTENANCE ACTIONS}

The objective of this phase is to group the maintenance activities to reduce the maintenance cost. For an $n$-component series system, the component maintenance activity can be considered as a collection of $G$. Each time the system shuts down, the decision of maintenance combination $G_{1}, G_{2}, \ldots G_{l}$ is a mutually exclusive subset of $G$, which satisfies

$$
\begin{aligned}
& G_{p} \cap G_{q}=\varnothing \quad p \neq q \\
& G_{1} \cup G_{2} \cup \ldots \cup G_{l}=G
\end{aligned}
$$

Coming to the number of the components increases, there's an exponential growth of the combination $G$. The candidates will become more complex. Whenever component $\mathrm{k}(\mathrm{k} \in\{1, \ldots \mathrm{n}\})$ reaches its reliability threshold $R_{k}$ and preventively maintained, all OM combinations will be simulated and the cost savings of this OM will be calculated. The OM combinations' total cost saving will be expressed as follows:

$$
C\left(G_{l}\right)=\sum_{i \in G_{l}} C_{S(i, k, j)} \quad i \neq k
$$

By comparing the different combinations of $C\left(G_{l}\right)$, the largest profit $C\left(G_{l}\right)$ can be selected as the optimal decision of the OM.

\section{PHASE 5: MAINTENANCE EXECUTION AND ROLLING-HORIZON UPDATE}

According to the previous step, the maintenance schedule has been determined. The maintenance actions are carried out based on the maintenance schedule. After that, phases (2) to (4) have been repeated when other components have reached its reliability threshold $(k=k+1)$. The OM schedule can be generated during the planning period. All the phases will be repeated if there are some changes in the working environment before the mission time.

Fig. 2. presents the procedure of OM optimization based on rolling horizon approach.

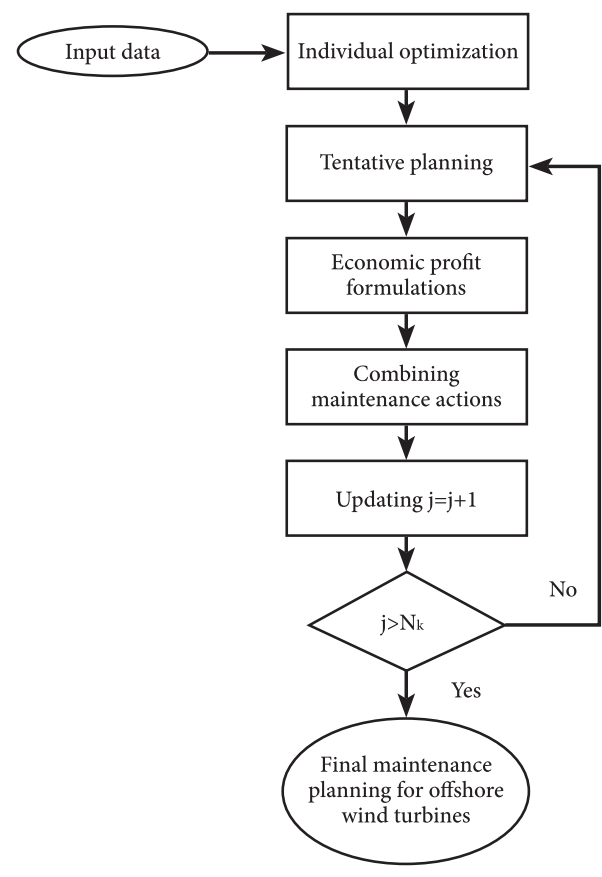

Fig. 2. Procedure of opportunistic maintenance strategy

\section{CALCULATION AND ANALYSIS}

\section{INPUT DATA}

All the OWTs in this research are aged between 3 to 10 years old. They are chosen from 5 to 10 farms in Europe. The nominal power is from 2 to $4 \mathrm{MW}$ while the rotor diameter is from $80 \mathrm{~m}$ to $120 \mathrm{~m}$, as a guide to the turbine type's size. The full data is extracted from the operational data of 1768 turbine years [4]. The onshore and offshore failure models are listed in Table 1 [23]

Tab. 1. Onshore and offshore failure models

\begin{tabular}{|c|c|c|c|c|}
\hline \multirow{2}{*}{ Component } & \multirow{2}{*}{ Distribution } & $\alpha($ day $)$ & & $\beta$ \\
\cline { 3 - 5 } & & Onshore & Offshore & \\
\hline Rotor & Weibull & 3000 & 1847 & 3 \\
\hline Gearbox & & 2400 & 1477 & 3 \\
\hline Generator & & 3300 & 1594 & 2 \\
\hline Pitch & & $1858^{\mathrm{a}}$ & 1144 & 3 \\
\hline
\end{tabular}

Tab. 2. Critical components of OWTs and cost parameters

\begin{tabular}{|c|c|c|c|c|c|c|}
\hline \multirow{2}{*}{ Component } & Cost of PM & Cost of CM & Fixed cost & Downtime cost & Duration of PM & Age reduction \\
\cline { 2 - 7 } & $\mathrm{C}_{\mathrm{pi}}$ & $\mathrm{C}_{\mathrm{mi}}$ & $\mathrm{C}_{0}$ & $\mathrm{C}_{\mathrm{di}}$ & \multicolumn{2}{c|}{ factor $\alpha_{\mathrm{i}}$} \\
\hline Rotor & 330 & 3000 & 30000 & 7500 & 5 & 0.008 \\
\hline Gearbox & 125 & 2500 & 30000 & 7500 & 3 & 0.006 \\
\hline Generator & 160 & 3500 & 30000 & 7500 & 3 & 0.005 \\
\hline Pitch & 210 & 1900 & 30000 & 7500 & 3 & 0.005 \\
\hline
\end{tabular}


Table 2 summarizes the properties of the OWT components and cost parameters. Assuming the capacity of analyzed OWT is $3 \mathrm{MW}$ and the electricity tariff (including tax) is $0.1 €$, the downtime cost during PM is $C_{d(i)}=3000 \times 24 \times 0.1=7200 € / \mathrm{d}$. The age reduction factor refers to the historical maintenance records, which are assumed as follows: rotor--0.008, gearbox--0.006, generator--0.005, pitch--0.005. The mission time $T$ is 1800 days (5 years).

\section{GROUPING MAINTENANCE PLANNING}

Based on the opportunistic group maintenance method proposed in Section 3, the maintenance information of the four components is simulated. Grouping maintenance planning results, considering perfect and imperfect maintenance for OWTs, are presented in Fig. 3 and Fig. 4 respectively.

The outcomes illustrate that the pitch ranks on top in terms of maintenance frequency. The explanation is that the pitch's statistical failure rate is beyond the other components. The pitch's preventive maintenances provide maintenance opportunities for other components when it reaches its reliability threshold as first.

The maintenance schedule for each component with perfect maintenance and imperfect maintenance are separately listed in the Table 3 and Table 4.

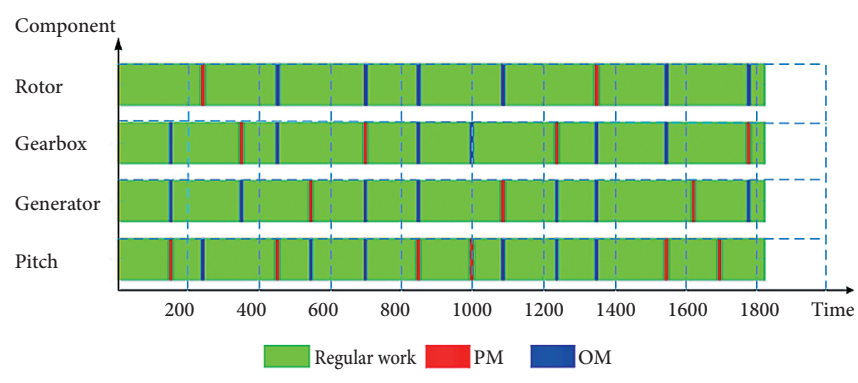

Fig. 3. Grouping maintenance planning for OWTs considering perfect maintenance

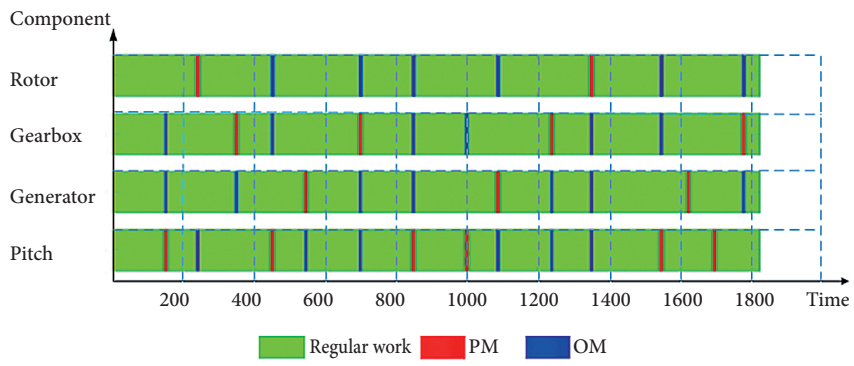

Fig. 4. Grouping maintenance planning for OWTs considering imperfect maintenance

Tab. 3. The maintenance schedule of each component considering perfect maintenance (days)

\begin{tabular}{|c|c|c|c|c|c|c|c|c|c|c|c|c|c|c|c|}
\hline Component & \multicolumn{15}{|c|}{ Time point for PM activity } \\
\hline Rotor & - & 237 & - & 447 & - & 697 & 847 & - & 1089 & - & 1356 & 1554 & - & - & 1786 \\
\hline Gearbox & 147 & - & 346 & 447 & - & 697 & 847 & 997 & - & 1242 & 1356 & 1554 & - & - & 1786 \\
\hline Generator & 147 & - & 346 & - & 545 & 697 & 847 & - & 1089 & 1242 & 1356 & - & 1631 & - & 1786 \\
\hline Pitch & 147 & 237 & - & 447 & 545 & 697 & 847 & 997 & 1089 & 1242 & 1356 & 1554 & - & 1693 & - \\
\hline
\end{tabular}

Tab. 4. The maintenance schedule of each component considering imperfect maintenance (days)

\begin{tabular}{|c|c|c|c|c|c|c|c|c|c|c|c|c|c|c|}
\hline Component & \multicolumn{14}{|c|}{ Time point for PM activity } \\
\hline Rotor & - & 237 & - & 447 & - & 695 & 845 & - & 1083 & - & 1347 & 1543 & - & 1775 \\
\hline Gearbox & 147 & - & 346 & 447 & - & 695 & 845 & 995 & - & 1235 & 1347 & 1543 & - & 1775 \\
\hline Generator & 147 & - & 346 & - & 542 & 695 & 845 & - & 1083 & 1235 & 1347 & - & 1620 & 1775 \\
\hline Pitch & 147 & 237 & - & 447 & 542 & 695 & 845 & 995 & 1083 & 1235 & 1347 & 1543 & 1620 & 1775 \\
\hline
\end{tabular}

Table 5 shows the comparison of maintenance times between perfect and imperfect maintenance for OWTs.

Tab. 5. Comparison of the maintenance times

\begin{tabular}{|c|c|c|c|c|}
\hline \multirow{2}{*}{ Component } & \multicolumn{2}{|c|}{ Imperfect maintenance } & \multicolumn{2}{c|}{ Perfect maintenance } \\
\cline { 2 - 5 } & PM & OM & PM & OM \\
\hline Rotor & 2 & 6 & 2 & 6 \\
\hline Gearbox & 4 & 6 & 4 & 6 \\
\hline Generator & 3 & 7 & 3 & 7 \\
\hline Pitch & 5 & 8 & 6 & 6 \\
\hline
\end{tabular}

The outcomes illustrate that the imperfect maintenance will shorten the components maintenance cycle. Comparatively speaking, the imperfect maintenance cycle is earlier than that of the perfect maintenance time. These two cases' maintenance combinations and the maintenance schedule are basically similar at the initial stage. However, with the passage of time, the maintenance combinations are quite different (Tab. 3 and Tab. 4). Focusing on the pitch, the maintenance cycle is shorter when the age reduction factor is introduced. The 11th maintenance is conducted on the $1543^{\text {th }}$ day. Immediately after that, the $12^{\text {th }}$ maintenance is conducted with generator on the $1620^{\text {th }}$ day. However, the $12^{\text {th }}$ maintenance for the perfect 
Tab. 6. Maintenance schedule and cost savings of each opportunistic maintenance for four components with imperfect maintenance

\begin{tabular}{|c|c|c|c|c|c|c|c|c|c|c|c|c|c|c|}
\hline \multirow{2}{*}{ Component } & & & & & & & & & & & & & & \\
\hline & 147 & 237 & 346 & 447 & 542 & 695 & 845 & 995 & 1083 & 1235 & 1347 & 1543 & 1620 & 1775 \\
\hline Rotor & - & $\mathrm{PM}$ & - & OM & - & OM & OM & - & OM & - & PM & $\mathrm{OM}$ & - & $\mathrm{OM}$ \\
\hline Gearbox & $\mathrm{OM}$ & - & PM & $\mathrm{OM}$ & - & PM & $\mathrm{OM}$ & $\mathrm{OM}$ & - & PM & $\mathrm{OM}$ & $\mathrm{OM}$ & - & PM \\
\hline Generator & $\mathrm{OM}$ & - & $\mathrm{OM}$ & - & PM & $\mathrm{OM}$ & $\mathrm{OM}$ & - & $\mathrm{PM}$ & $\mathrm{OM}$ & $\mathrm{OM}$ & - & $\mathrm{PM}$ & $\mathrm{OM}$ \\
\hline Pitch & PM & $\mathrm{OM}$ & - & PM & $\mathrm{OM}$ & $\mathrm{OM}$ & $\mathrm{PM}$ & $\mathrm{PM}$ & $\mathrm{OM}$ & $\mathrm{OM}$ & $\mathrm{OM}$ & $\mathrm{PM}$ & $\mathrm{OM}$ & $\mathrm{OM}$ \\
\hline $\mathrm{C}\left(\mathrm{G}_{1}\right) / €$ & $3.58 \mathrm{E}+04$ & $1.31 \mathrm{E}+03$ & $1.31 \mathrm{E}+04$ & $1.69 \mathrm{E}+03$ & $4.14 \mathrm{E}+03$ & 4.14E+04 & $3.19 \mathrm{E}+04$ & $6.89 \mathrm{E}+03$ & $5.76 \mathrm{E}+03$ & $2.29 \mathrm{E}+04$ & $2.50 \mathrm{E}+04$ & $1.57 \mathrm{E}+04$ & $2.72 \mathrm{E}+03$ & $1.85 \mathrm{E}+04$ \\
\hline
\end{tabular}

Tab. 7. Maintenance schedule and cost savings of each opportunistic maintenance for onshore WT system with imperfect maintenance

\begin{tabular}{|c|c|c|c|c|c|c|c|c|c|}
\hline \multirow{2}{*}{ Component } & 1 & 2 & 3 & 4 & 5 & 6 & 7 & 8 & 9 \\
\cline { 2 - 11 } & 237 & 384 & 562 & 714 & 951 & 1123 & 1376 & 1556 & 1772 \\
\hline Rotor & - & $\mathrm{PM}$ & - & $\mathrm{OM}$ & - & $\mathrm{OM}$ & $\mathrm{OM}$ & - & $\mathrm{OM}$ \\
\hline Gearbox & $\mathrm{OM}$ & - & $\mathrm{PM}$ & $\mathrm{OM}$ & - & $\mathrm{PM}$ & $\mathrm{PM}$ & $\mathrm{OM}$ & $\mathrm{OM}$ \\
\hline Generator & $\mathrm{OM}$ & - & - & $\mathrm{OM}$ & - & $\mathrm{OM}$ & - & $\mathrm{PM}$ & $\mathrm{OM}$ \\
\hline Pitch & $\mathrm{PM}$ & $\mathrm{OM}$ & - & $\mathrm{PM}$ & $\mathrm{PM}$ & $\mathrm{OM}$ & $\mathrm{OM}$ & $\mathrm{OM}$ & $\mathrm{PM}$ \\
\hline $\mathrm{C}\left(\mathrm{G}_{1}\right) / €$ & $2.45 \mathrm{E}+04$ & $2.18 \mathrm{E}+03$ & 0 & $2.67 \mathrm{E}+04$ & 0 & $3.57 \mathrm{E}+04$ & $2.75 \mathrm{E}+04$ & $2.55 \mathrm{E}+04$ & $2.40 \mathrm{E}+04$ \\
\hline
\end{tabular}

maintenance is conducted on the $1693^{\text {th }}$ day. During the general planning cycle of the pitch, there are one less PM and two more OM in the imperfect maintenance (Tab. 5). This guarantees the reliability and safety of the pitch. As described in section 1, PM activity generally doesn't prove to be perfect in restoring the system back to form, hence, the application of imperfect maintenance in this paper is more realistic and precise.

\section{ECONOMIC PROFIT ANALYSIS}

Table 6 shows the maintenance schedule and the cost savings of each OM for four components with imperfect maintenance. It is concluded that the maintenance expenses are significantly decreased through OM for OWTs. According to the maintenance schedule, all the four components of OWT system are maintained together at time $695^{\text {th }}$ day, $845^{\text {th }}$ day, $1347^{\text {th }}$ day and $1775^{\text {th }}$ day. The most cost saving is $44086.0 €$ on the $695^{\text {th }}$ day when the $6^{\text {th }} \mathrm{OM}$ is performed. The total cost savings in the mission time ( $T=1800$ days) is $245304.2 €$ and the average daily cost savings is $136.3 €$ when the OM strategy is implemented. Maintenance expense decreases from $292.7 €$ to $156.4 €$ in terms of the OWT system, indicating that $46.6 \%$ of the cost is conserved.

Fig. 5 presents the proportion of maintenance costs. Pitch occupies $36 \%$ of the overall expenses owing to its high failure

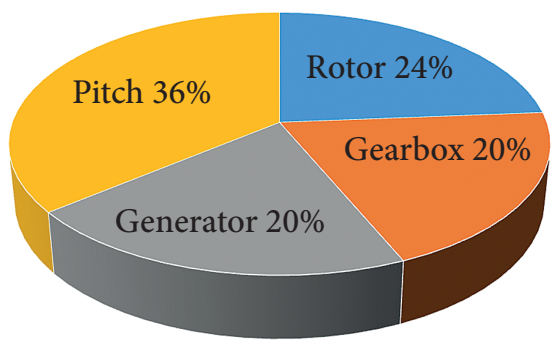

Fig. 5. Proportion of maintenance costs rate and maintenance cost. Therefore, the maintenance plan of pitch should be well treated.

The OWTs' failure rates are comparatively higher than that of the onshore ones obviously because of the harsh marine conditions [4]. The maintenance activities' fixed costs are dramatically different as the OWTs are equipped with specific transportation resources. Grouping maintenance information of onshore WTs is diagramed in Fig. 6. based on statistical failure rate and maintenance costs [9]. The maintenance schedule and the cost savings of each opportunistic maintenance for onshore WT system with imperfect maintenance is shown as Table 7.

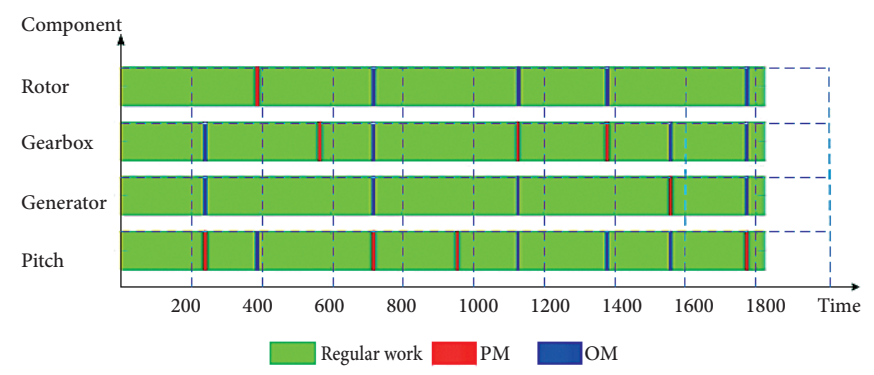

Fig. 6. Grouping maintenance planning with imperfect maintenance for onshore WT system

To conclude, the maintenance expenses are also dramatically reduced via the OM. There are $92.3 €$ being saved every day. It is deserving to notice that the onshore WTs' OM times are comparatively less than that of the OWTs as it has lower failure rate.

Fig. 7 presents a comparison between the onshore and offshore WTs system. Because of the application of the OM, the maintenance expense of the onshore WTs system reduces from $237.4 €$ to $145.1 €$, this implies that $38.9 \%$ of the cost has been conserved. Just like what is mentioned in point 4.3 , the maintenance expense drops from $292.7 €$ to $156.4 €$ in the OWT 
system, signifying that there are $46.6 \%$ of the cost conserved. The outcomes illustrate the OM necessity, especially for the OWTs.

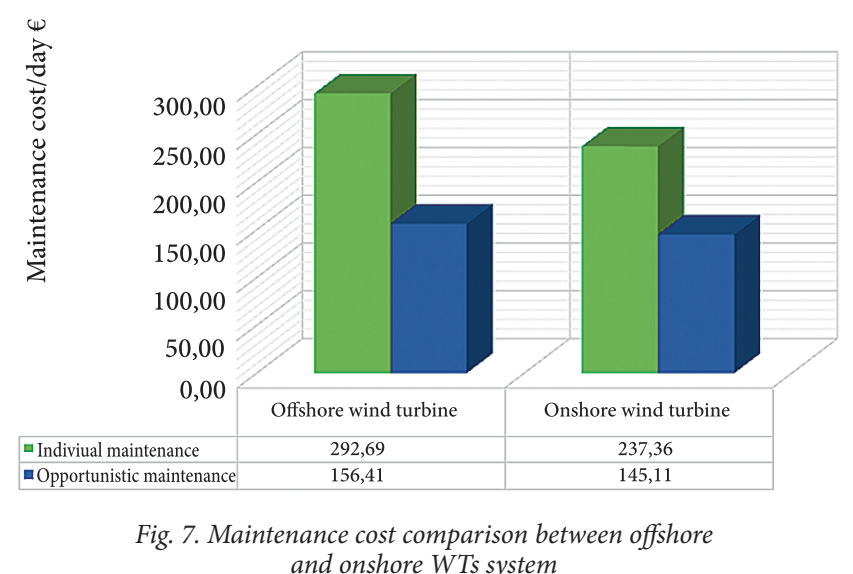

CONCLUSIONS

This paper promotes an opportunistic PM scheduling method according to dynamic programing, taking the imperfect maintenance and the PM durations into consideration. The economic advantage has been illustrated. The age reduction factor has been introduced in the description of the PM activities. The input data are obtained from previous studies. Maintenance schedule during the mission time has been decided through the selection of the best combination.

In the overall planning cycle of the pitch, the case of imperfect maintenance has two more OM and one less PM than the perfect maintenance which ensures the safety and reliability. The pitch has the highest maintenance frequency and it occupies $36 \%$ of the overall expenses owing to its high failure rate and maintenance cost. Therefore, the maintenance plan of pitch should be well treated. The researches which are 6, 6, 7, 8 times of OM are implemented respectively to pitch, generator, gearbox and rotor if the grouped maintenance planning has been adopted. The total cost savings in the mission time ( $\mathrm{T}=1800$ days) is $245304.2 €$, and average daily maintenance expense decreases from $292.7 €$ to $156.4 €$ for the OWTs system, indicating that $46.6 \%$ of the cost is conserved. With the application of the $\mathrm{OM}$, the maintenance expense of the onshore WTs system reduces from $237.4 €$ to $145.1 €$, which implies that $38.9 \%$ of the cost has been conserved. The necessity of OWTs OM is demonstrated through the expense comparison between onshore and offshore WTs.

More detailed studies are needed so that the maintenance planning can be improved, which includes the discussion on the relevant failures and component dependencies, considering the limited available repairmen effect. The proposed method will hopefully be extended to the offshore wind farms.

\section{ACKNOWLEDGMENTS}

This work has been supported by the National International Science and Technology Cooperation Specific Project, the Development of risk assessment software for floating offshore wind turbine (No. 2013DFE73060) and the development of failure database and risk assessment system for FPSO (No. G014614002).

\section{REFERENCES}

1. Arshad, M., O'Kelly, B.C.: Offshore wind-turbine structures: a review. Proc. Inst. Civ. Eng. Energy 2013.166 (4) 139-152.

2. Besnard, F., Bertling, L.: An approach for condition-based maintenance optimization applied to wind turbine blades. IEEE Trans. Sustain. Energy 2010, 1 (2) 1-7.

3. Carlos, S., Sanchez, A., Martorell, S., Marton, I.: Onshore wind farms maintenance optimization using stochastic model. Math. Comput. Model. 2013, 57 (708) 1884-1890.

4. Carroll, J., McDonald, A.: Failure rate, repair time and unscheduled O\&M cost analysis of offshore wind turbines. Wind Energy. 2015, 19 (6) 1107-1119.

5. Chandler, H.: Wind Energy - The facts, European Wind Energy Association. 2003.

6. Ding, F., Tian, Z.: Opportunistic maintenance optimization for wind turbine systems considering imperfect maintenance actions. Int. J. Reliab. Qual. Saf. Eng. 2011, 18 (5) 1-18.

7. Ding, F., Tian, Z.: Opportunistic maintenance for wind farms considering multilevel imperfect maintenance thresholds. Renew. Energy 2012, 45 (1) 175-182.

8. European Wind Energy Association. Wind in power, 2014 European statistics. 2015.

9. Faulstich, S., Hahn, B., Tavner, P. J.: Wind turbine downtime and its importance for offshore deployment. Wind Energy, 2011, (14), 327-337.

10. Hameed, Z.: Role of grouping in the development of an overall maintenance optimization framework for offshore wind turbines. Proc. Inst. Mech. Eng. Part O J. Risk Reliab. 2012, 226 (6) S1, 584-601.

11. Hameed, Z., Hong, Y.S., Cho, Y.M., Ahn, S.H., Song, C.K.: Condition monitoring and fault detection of WTs and related algorithms: A review. Renew. Sustain. Energy Rev. 2009, 1-39.

12. Hau, E.: Wind Turbines: Fundamentals, Technologies, Applications, Economics, Springer, Sidcup, Kent, UK, 2006.

13. Herbert, G.M.J., Iniyan, S., Sreevalsan, E., Rajapandian, S.: A review of wind energy technologies, Renew. Sustain. Energy Rev. 2007, (11) 1117-1145.

14. Jamieson, P.: Innovation in wind turbine design. Wiley, England, 2011. 
15. Kahrobaee, S., Asgarpoor, S.: A hybrid analytical-simulation approach for maintenance optimization of deteriorating equipment: case study of wind turbines. Electr. Power Syst. Res. 2014, 104 (1) 80-86.

16. Kang, J.C., Sun, L.P., Sun, H., Wu. C.L.: Risk assessment of floating offshore wind turbine based on correlation-FMEA. Ocean Engineering 2017, (129), 382-388.

17. Karyotakis, A., Bucknall, R.: Planned intervention as a maintenance and repair strategy for offshore wind turbine. J. Mar. Eng. Technol. 2010, A 16 27-35.

18. Laggoune, R., Chateauuneuf, A., Aissani, D.: Opportunistic policy for optimal preventive maintenance of a multicomponent system in continuous operating units. Comput. Chem. Eng. 2009, 33 (9) 1499-1510.

19. Laura, C.S., Vincente, D.C.: Life-cycle cost analysis of floating offshore wind farms. Wind Energy, 2014, 66 (1) 41-48.

20. Liu, W., Tang, B., Jiang, Y.: Status and problems of WT structural health monitoring techniques in China. Renew. Energy 2010, (35) 1414-1418.

21. Nielsen, J.J., Sorensen, J.D.: On risk-based operation and maintenance of offshore wind turbine components. Reliab. Eng. Syst. Saf. 2011,96 (1) 218-229.

22. Nilsson, J., Bertling, L.: Maintenance management of wind power systems using condition monitoring systems-life cycle cost analysis for two case studies. IEEE Trans. Energy Convers. 2007, 22 (1) 223-229.

23. Santos, F., Teixeira, A.P., Guedes Soares, C.: Modelling and simulation of the operation and maintenance of offshore wind turbines. Journal of Risk and Reliability, 2015, Vol.229 (5) 385-393.

24. Shafiee, M.: An opportunistic condition-based maintenance policy for offshore wind turbine blades subjected to degradation and environmental shocks. Reliab. Eng. Syst. Saf. 2015, 463-471.

25. Shafiee, M.: Maintenance logistics organization for offshore wind energy: current progress and future perspectives. Renew. Energy 2015, 77, 182-193.

26. Snyder, B., \& Kaiser, M.: Ecological and economic costbenefit analysis of offshore wind energy. Renewable Energy, 2009, 34(6), 1567-1578.

27. Sorensen, J.D.: Framework for risk-based planning of operation and maintenance for offshore wind turbines. Wind Energy, 2009, 12 (5) 493-506.
28. Spinato, F., Tavner, P.J., van Bussel, G.J.W., Koutoulakos, E.: IET Reliability of WT subassemblies. Renew. Power Gener. 2009, 3 (4) 387-401.

29. Stiesdal, H.: The wind turbine components and operation. Bonus Info, newsletter special issue, Bonus Energy A/S, Brande. 1999.

30. U.S. Energy Information Administration: Levelized cost and levelized avoided cost of new generation resources in the annual energy outlook. 2014.

31. Walford, C.: Wind turbine reliability: understanding and minimizing wind turbine operation and maintenance costs. Sandia report, SAND2006-1100. National Laboratories. 2006.

32. Wildeman, R.E., Dekker, R., Smit, A.C.J.M.: A dynamic policy for grouping maintenance activities. European Journal of Operation Research 1997, 99(3), 530-551.

33. Zhang,X., Sun,L.P.: Floating offshore wind turbine reliability analysis based on system grading and dynamic FTA. J. Wind Eng.Ind.Aerodyn. 2016, (154) 21-33.

\section{CONTACT WITH THE AUTHOR}

\author{
Yang Lu
}

e-mail:luyang071471@126.com

Harbin Engineering University, Nantong Street Nangang District., 150001 Harbin

China

\section{Linping Sun}

e-mail: sunliping196206@126.com

Harbin Engineering University, Nantong Street Nangang District., 150001 Harbin

\section{China}

\section{Jichuan Kang}

e-mail: jasonkang@163.com

Harbin Engineering University, Nantong Street Nangang District., 150001 Harbin

\section{China}

\section{Xinyue Zhang}

e-mail: zhangxinyue071471@126.com

Heilongjiang Water Transport Planning and Design Institute, Nantong Street, Nangang District. 150001 Harbin

China 